\title{
ARTIGOS
}

\section{RESIDÊNCIA PEDAGÓGICA: UMA DISCUSSÃO EPISTEMOLÓGICA}

\author{
Kátia Augusta Pinheiro Cordeiro CURADO SILVA \\ Universidade de Brasilia - UnB \\ Brasilia, DF-Brasil \\ E-mail katiacurado@unb.br \\ ORCID - https://orcid.org/0000-0002-9808-4577
}

\begin{abstract}
RESUMO: O presente texto objetiva apresentar, de maneira ampla, elementos teóricos e metodológicos sobre a configuração da Residência Pedagógica numa perspectiva crítica emancipadora.O estudo se justifica a partir da compreensão de que a formação de professores tem se constituído, ao longo das últimas décadas, como umaimportante pauta no contexto das políticas educacionais desenvolvidas em diferentes países. Por ser considerada como aspecto fundamental para a construção da qualidade na educação, importa-nos discutir a Residência Pedagógica como um dos elementos políticos e pedagógicos da formação que traduzem diferentes valores, princípios e projetos de sociedade. Para tanto, são apresentadas, inicialmente, discussões sobre formação de professores; seguidas da análise conceitual da Residência Pedagógica e a discussão de uma proposta crítica emancipadora. Este caminho,referenciado em estudos bibliográficos sobre atemática, proporcionou desvelar elementos presentes nos projetos de formação de professores que atravessaram historicamente o modo que estes se constituem no Brasil.Dialeticamente,buscou-se estabelecer o desenvolvimento do projeto de formação comprometido com a humanização e a emancipação dos sujeitos, numa perspectiva dialógica que reconhece a educação como uma prática social situada e que toma, como ponto de partida, os contextos de vivência dos sujeitos de forma a construir propostas prenhes de sentido e significado para quem delas participa.
\end{abstract}

PALAVRAS-CHAVE: Residência pedagógica, princípios, formação de professores

\section{PEDAGOGICAL RESIDENCE: NA EPISTEMOLOGICAL DISCUSSION}

\begin{abstract}
This text aims to present, in a broad way, theoretical and methodological elements about the configuration of the Pedagogical Residence in a critical emancipatory perspective. The study is justified based on the understanding that teacher training has been constituted, over the last decades, as an important agenda in the context of educational policies developed in different countries. Because it is considered as a fundamental aspect for the construction of quality in education, it is important for us to discuss the Pedagogical Residence as one of the political and pedagogical elements of training that translate different values, principles and projects of society. To this end, discussions on teacher training are initially presented; followed by the conceptual analysis of the Pedagogical Residence and the discussion of a critical emancipatory proposal. This path, referenced in bibliographic studies on the subject, provided the opportunity to reveal elements present in teacher education projects that historically crossed the way they are constituted in Brazil. Dialectically, it was sought to establish the development of the training project committed to the
\end{abstract}


humanization and emancipation of the subjects, in a dialogical perspective that recognizes education as a situated social practice and that takes, as a starting point, the contexts of experience of the subjects of in order to build proposals full of meaning and meaning for those who participate in them.

KEYWORDS: Pedagogical residency, principles, teacher education

\section{RESIDENCIA PEDAGÓGICA: UMA DISCUSIÓN EPISTEMOLÓGICA}

RESUMEN: El presente texto tiene como objetivo presentar, de manera amplia, elementos teóricos y metodológicos sobre la configuración de la Residencia Pedagógica en una perspectiva crítica emancipadora. El estudio se justifica a partir del entendimiento de que la formación del profesorado se ha constituido, en las últimas décadas, como una agenda importante en el contexto de las políticas educativas desarrolladas en diferentes países. Por considerarla uno de los aspectos fundamentales para la construcción de la calidad de la educación, entonces nos importa discutir la Residencia Pedagógica como uno de los elementos políticos y pedagógicos de la formación que traducen diferentes valores, principios y proyectos de sociedad. Para eso se presentan inicialmente debates sobre la formación del profesorado; seguido de un análisis conceptual de la Residencia Pedagógica y la discusión de una propuesta crítica emancipadora. Este camino, referenciado en estudios bibliográficos sobre temática, ha permitido develar elementos presentes en proyectos de formación docente que históricamente han se constituido en Brasil. Dialécticamente, se buscó establecer el desarrollo del proyecto formativo comprometido con la humanización y emancipación de sujetos, en una perspectiva dialógica, que reconoce la educación como una práctica social situada y que toma como base los contextos de vivencia de los sujetos con el fin a construir propuestas llenas de sentido y significado para quienes de ellas participan.

PALABRAS CLAVE: Residencia pedagógica, principios, formación docente 


\section{Introdução}

Esse artigo tem o propósito de contribuir com o debate sobre a Residência Pedagógica (RP) para a formação inicial dos professores,apresentando elementos teóricos e metodológicos que a configurem numa perspectiva crítica emancipadora. Para tanto, foi necessário um estudo bibliográfico do tema e diferentes narrativas sobre as experiências ocorridas no Brasil. Considero dois exemplos de RP para a realização deste estudo, sendo: i) O Programa de Residência Pedagógica (PRP) da Coordenação de Aperfeiçoamento de Pessoal de Nível Superior - Fundação CAPES; ii) A RP da Escola de Filosofia, Letras e Ciências Humanas da Universidade Federal de São Paulo (EFLCH/Unifesp-Campus Guarulhos) que desenvolve, desde 2009, no curso de Pedagogia, a Residência Pedagógica na perspectiva de um programa de estágio, caracterizado, de acordo com o projeto, por um progressivo contato sistemático entre os estudantes, os professores da IES e das escolas de educação básica. Embora existam outras experiências ${ }^{1}$ de RP, estas têm as caraterísticas importantes de serem consideradas, que são: a) estarem vinculadas àformação inicial;b) terem processualidade e continuidade; e c) contarem com um número expressivo de estudantes das universidades públicas, dos Institutos Federais e de instituições confessionais.

A formação de professores tem se constituído, ao longo das últimas décadas, como um campo amplo de construção de conhecimentos que coloca em discussão diferentes perspectivas teóricas e metodológicas que nos permitem compreender a complexidade presente nos atos educativos. Tal diversidade é perpassada por questões políticas, culturais e econômicas, entre outras, que configuram a educação como uma prática social situada, na qual se evidenciam compromissos com diferentes projetos de sociedade e de homem, portanto que apresenta diferentes projetos em disputa.

Historicamente, a formação de professores se assentou numa racionalidade técnica que reduzia a figura do professor à de consumidor de conhecimentos e um executor de planos e pautas elaborados por especialistas. Tal perspectiva entendia a relação teoria e prática numa perspectiva aplicacionista, em que o professor executava a prática pedagógica a partir de modelos instrucionais.A partir dos anos de 1990, entra no Brasil a epistemologia da prática para a formação de professores que traz questões contraditórias, como o reconhecimento da especificidade do saber docente e, ao mesmo tempo, uma responsabilidade pelas "reflexões" no cotidiano escolar com vistas a resolver problemas que, na maioria das vezes, são estruturais, colocando a relação teoria e prática numa perspectiva pragmática, em que a prática e seus resultados úteis e imediatos é que constituem o saber e a direção da atividade pedagógica (CURADO SILVA, 2008). Entendemos estarem nesse projeto as propostas dos PRP da Capes (BRASIL, 2018; 2020).

Entretanto, na dialeticidade histórica e na luta contra-hegemônica, outros processos e projetos também são construídos e confrontadosna realidade, aqui especificamente, na formação de professores. Refiro-me aum conjunto de propostas e elementos que denomino de epistemologia da práxis na formação de professores (CURADO SILVA, 2019) que colabora para a construção de uma prática pedagógica pautada no reconhecimento dos professores como sujeitos autônomos, em que a capacidade de vivenciar a relação teoria e prática em sua unidade constitui uma práxis criativa e revolucionária. Essa epistemologia compreende que os professores são sujeitos históricos, portadores e construtores de cultura que têm a capacidade de produzir conhecimento relevante sobre a educação a partir da problematização calcada numa sólida formação teórica que permite a reflexão coletiva e crítica das práticas vivenciadas em seus contextos de origem e que se encontram perpassadas por determinantes distintas que tornam tensos e contraditórios os espaços educativos. 
É a partir da disputa hegemônica que este estudo busca situar a Residência Pedagógica, assumindo princípios conceituais-práxicos. Existem diferentes publicaçõescomo as de Curado Silva e Cruz (2018);Curado Silva (2018); Fariae Diniz-Pereira (2019); e Costa (2020), por exemplo,que apresentam e estudam o Residência Pedagógica a fim de historicizar as propostas no Brasil e compreender os aspectos que dimensionam a experiência resultado da proposta PRP/Capes (BRASIL, 2018). A partir dessas investigações, embora entendamose reforcemosa necessidade de ampliar os estudos e pesquisas sobre o tema, recortamos, para esse estudo, a opção de trabalhar com o que denominamos de princípios conceituais-práxicos tomados como fundamento ou essência do fenômeno, com a finalidade de problematizar e subsidiar elementos para uma práxis na Residência Pedagógica numa proposta contra-hegemônica.

\section{Princípios formativos para a Residência Pedagógica}

O Estado ampliado corresponde à sociedade política e à sociedade civil, sendo a primeira (Estado em sentido estrito) formada pelo conjunto dos mecanismos através dos quais a classe dominante detém o monopólio legal da repressão e da violência e que se identifica com os aparelhos coercitivos ou repressivos de Estado controlados pelas burocracias. Já a sociedade civil é representada pelas organizações responsáveis pela elaboração e/ou difusão das ideologias, compreendendo as escolas, as igrejas, os partidos políticos, os sindicatos, as organizações profissionais, os meios de comunicação etc. No meio e por meio da sociedade civil, busca-se a hegemonia, cujos portadores materiais são os aparelhos privados de hegemonia. Neste contexto, afigura-se imprescindível a estratégia da guerra de posição que vem a ser a conquista de posições importantes para a construção da hegemonia. Por conseguinte,

[...] a teoria ampliada do Estado é a base que permite a Gramsci responder de modo original à questão do fracasso da revolução nos países ocidentais: esse fracasso ocorreu, supõe Gramsci, porque não se levou na devida conta a diferença estrutural que existe entre, por um lado, as formações sociais do 'Oriente' (entre as quais se inclui a Rússia czarista), caracterizada pela debilidade da sociedade civil em contraste com o predomínio quase absoluto do Estado-coerção; e por outro, as formações sociais do 'Ocidente', onde se dá uma relação mais equilibrada entre sociedade civil e sociedade política, ou seja, onde se realizou concretamente a 'ampliação' Estado (COUTINHO, 1989, p.89).

A guerra de posição, por sua vez, corresponde à conquista de posições importantes para a construção da hegemonia. Não a tomemos no senso comum, como ocupação de espaços ou brechas, mas sim à organização de grupos representativos da sociedade civil que ocupam determinados espaços. Essa perspectiva político-estratégica suscita a gradativa, incessante e progressiva erosão dos fundamentos de dominação e direção do capitalismo, permitindo, em um primeiro momento, a conquista pelos grupos oprimidos de sua hegemonia ético-política sobre o conjunto das instituições sociais.

Nesse sentido,entendemos que a perspectiva da guerra de posição, referente a programas de formação de professores, exige uma articulação das entidades, universidades e movimentos associativos em prol de tomar/ assumir a direção do Programa Residência Pedagógica numa perspectiva coletiva e institucional. Trabalhando nessa construção, apresento alguns princípios que podem orientar a posição de caráter emancipador para a Formação de Professores na Residência Pedagógica e, assim, proponhoseis princípios, sendo eles: i) unidade teoria e prática - práxis; ii) alternância;iii)trabalho pedagógico;iv)o processo de ensinar/aprender;v) autonomia didático-pedagógica;e vi) profissionalidade docente. 
Assim, não vou discutir especificamente o PRP em si, mas os princípios que devem orientar a práxis do desenvolvimento de uma atividade residente na formação inicial de professores. Embora a maioria das atividades esteja vinculada a um edital do governo e tenha orientações para a sua execução aliadas a um projeto de formação em disputa, entendo ser o papel da formação, portanto dos formadores e formandos, traçar projetos formativos na perspectiva do caráter emancipador.É dessa forma que construo este artigo, apresentando princípios gerais que entendo que devem ser parte constitutiva da práxis de todos os envolvidos na Residência Pedagógica.

\section{Unidade teoria e prática - práxis}

A relação teoria e prática é central em qualquer programa de Residência Pedagógica. A questão é entender como se propõe e/ou mesmo se materializa a proposta.Na relação teoria-prática, manifestam-se os problemas e as contradições da sociedade em que vivemos que, como sociedade capitalista, privilegia a separação trabalho intelectual e trabalho manual e, consequentemente, a separação entre teoria e prática. Segundo Candau e Lelis (1999), a relação entre teoria e prática pode ser fundamentada em três esquemas: a visão dicotômica, a visão associativa e a visão de unidade.

Na visão dicotômica, está centrada na separação entre teoria e prática com ênfase na total autonomia de uma em relação à outra. É uma visão mais extremista, na qual a teoria e a prática são componentes isolados e mesmo opostos. Caberia aos teóricos, então, pensar, elaborar, refletir, planejar; e aos práticos, executar, agir e fazer, tendo, cada um desses, um pólo e sua lógica própria. Tal perspectiva vai entender, por exemplo, que a Universidade é o lugar da teoria e a Escola, o lugar da prática. O projeto de RP,que trabalhar nessa perspectiva, separa dois espaços teóricos/práticos que formam o professor, provocando uma cisão na compreensão da realidade e no papel da função do professor e da escola, o que compromete a própria compreensão da realidade.

Já em uma visão associativa, tomada muitas vezes de forma aplicacionista, estes pólos não são opostos, mas tem uma relação direta de imediaticidade. A prática deve ser uma aplicação da teoria e só adquirirá relevância na medida em que for fiel aos parâmetros desta, ou mesmo ao contrário, a referência é a prática, e é por meio dela que se valida a teoria, ou seja, a teoria verdadeira é aquela que é útil de forma imediata. É preciso ressaltar que há um componente pragmático na visão associativa,pois a formação prática tem sua lógica própria, que independe da teoria. Neste caso, a prática é esvaziada da teoria e, por issohá a ênfase nas disciplinas instrumentais, sem a preocupação com sua articulação com as disciplinas consideradas teóricas. Se tomarmos essa perspectiva associativa/aplicacionista para a RP, como compreendo ser a proposta do edital da Capes (BRASIL, 2020), uma vez que a referência de prática é a aplicação da Base Nacional Comum - BNCC e que as metodologias que possam viabilizar as competências e habilidades previstas neste currículo restringema formação inicial a vivências de práticas utilitárias circunscritas à atuação dos residentes na promoção e elaboração de atividades específicas em cada área de conhecimento. É, sobretudo, uma formação neotecnicista-instrumental dirigida para a solução de problemas, mediante a aplicação de teorias e técnicas científicas, e com exigência de flexibilidade e criatividade na sua aplicação. O foco na formação prática tem uma lógica própria que independe da teoria: é o esvaziamento teórico da formação e da atuação docente.

O que propomos como princípio para a Residência Pedagógica é a relação entre teoria e prática centrada na articulação dialética entre ambas, o que não significa, necessariamente, uma identidade entre elas; significa uma relação que se dá na contradição, ou seja, expressa um movimento de interdependência em que uma não existe sem a outra. É necessário que o educador compreenda que teoria e prática não se separam, 
isto é, o vínculo teoria e prática forma um todo em que o saber tem um caráter libertador. Com isso, Freire (1979, p. 149) nos mostra que

É preciso que fique claro que, por isto mesmo que estamos defendendo a práxis, a teoria do fazer, não estamos propondo nenhuma dicotomia de que resultasse que este fazer se dividisse em uma etapa de reflexão e outra, distante, de ação. Ação e reflexão e ação se dão simultaneamente.

Nessa visão de unidade, teoria e prática são dois componentes indissolúveis da "práxis" definida como atividade teórico-prática, ou seja, tem um lado explicativo, intencional, teórico e um lado material, propriamente prático, com a particularidade de que só artificialmente, por um processo de abstração, pode se separar um do outro. Essa relação não é direta nem imediata, fazendo-se através de um processo complexo, no qual algumas vezes se passa da prática à teoria e outras desta à prática (VASQUEZ, 1977).Como princípio da Residência Pedagógica, a práxis exige que a atividade pedagógica de formação tenha a intenção/ideia e a ação como processos indissociáveis no fazer docente, pois o ato pedagógico é sempre intencional e o docente necessita da clareza consciente de sua intencionalidade, transformando-o em ação na medida que também essa ação transforma o seu fazer e a si próprio numa direção de caráter emancipador.

Nessa perspectiva, auniversidade e a escola são espaços teóricos e práticos de formação, pois, na universidade, elaboram-se elementos intencionais e explicativos da ação docente e, na escola,são elaboradas as intencionalidade e a ação docente. A teoria é a forma como o conhecimento se apresenta articulando-se sistematicamente em graus e especificidades, disposto a explicar ou ilustrar ações práticas; enquanto a prática é a própria constituição da teoria, formulada em ações concretas, podendo ser modificada e modificar as teorias e os sujeitos em suas práticas. Observa-se que a teoria e a prática pedagógica estão estreitamente ligadas por um fio que conduz ao ensino, porém vale salientar que a dimensão teórica e prática não está presente apenas nos espaços educacionais, mas em todo o exercício que direciona o sujeito à ação.

Esse processo na RP, tomado como práxis, seria a formação e a atuação docentes referenciadas na prática e na teoria pedagógica, num movimento em que ação do fazer docente retorna de forma reflexiva para a teoria, num processo de amadurecimento e aperfeiçoamento de suas ações docentes.Assim, estaria a teoria também amadurecida, reflexiva e humanizada, com uma prática significativa, modificada e que modifica também o sujeito e seu contexto.

\section{Alternância}

Trabalhando na perspectiva da práxis, a Alternância se torna um princípio de formação, na concepção de articulação entre os espaços formativos da universidade pública e da escola pública. Embora como projeto em disputa haja outras proposições, como por exemplo a de Zeichner (2010, p. 487), que utiliza a expressão terceiros espaços, sendo que estes [...] reúnem o conhecimento prático ao acadêmico de modos menos hierárquicos, tendo em vista a criação de novas oportunidades de aprendizagem para professores em formação".

Assumo outra perspectiva da relação entre a universidade e a escola, pois não entendo que devam ser colocadoscomo setores de formação na busca de um espaço neutro e menos hierarquizado, mas os compreendo como elementos e espaços de identidades únicas em que ambos formam o docente. Também refuto a tese da formação em serviço, pelo viésda intensificação do trabalho docente que pode ocorrer, ou mesmo devido à necessidade da suspensão do cotidiano (DUARTE,2014) para a própria elaboração da práxis. 
Dessa forma, assumo, para a Residência Pedagógica, o princípio da Alternância que é vista como uma maneira de pensar os diferentes espaços formativos que possibilitam ao sujeito aprender e apreender situações de aprendizagem em espaços formais de ensino, bem como em espaços de vida e trabalho. Conhecer a Alternância implica em reconhecê-la como ponto fundante do processo de articulação entre vida e trabaIho, suas peculiaridades, seus princípios e instrumentos aliados à cultura na qual o sujeito reconhece a sua história e a sua ação nos espaços onde vive e/ou trabalha.A Alternância tem início com ênfase em uma educação que articule escola, família e trabalho, na perspectiva de manter o jovem no campo(Queiroz, 2004; Estevam 2003). A ideia inicial apontava para a necessidade de alternar os tempos educativos, priorizando os conteúdos básicos a serem ensinados durante o tempo em que os jovens permaneciam na escola e, na comunidade, realizando atividades agrícolas para o desenvolvimento econômico do campo, bem como para seu desenvolvimento social e aprendizado. É nesse princípio que se baseia a formação de professores na Educação do campo.

Assim, como pensar a alternância na residência pedagógica? Trabalhando na perspectiva de que a universidade é espaço de formação e a escola também o é, sem hierarquia, entendendo que a universidade promove um conhecimento teórico-prático sobre a atuação docente e a escola promove o mesmo conhecimento, entretanto, como lugar do trabalho pedagógico. Ao vivenciar o movimento da Alternância, em espaços revezados, compreende-se que é dada a oportunidade de potencializar a aprendizagem, pois são estabelecidas condições de articular o que é do cotidianodo trabalho docente aos conceitos sistematizados na educação formal, uma vez que se reconhece a necessidade de concretizar as suas experiências em tempos e espaços diversos. Esta educação engloba temas referentes à vida da formação universitária, à formação integral nos meios profissional, social, político e econômico.

A Pedagogia da Alternância, a partir deinstrumentos específicos de alternar os espaços de formação, sinaliza que educadores e educandos devem romper com uma perspectiva conservadora e inclusive investir na reflexão teoria-prática, pois a alternância entre os espaços formativos indica a possibilidade de envolvimento crítico na produção do conhecimento,o que apresenta um caráter emancipador, pois permite a apropriação de diferentes realidades e visões de mundo. As práticas de alternância e, nelas, a formação do educador, podem resultar em mudanças, uma vez que a vinculação com o mundo do trabalho e sua reflexão das práticas cotidianas podem se constituir em elementos de confronto de crenças, comportamentos e conhecimentos.

Esta é, em nossa percepção, uma forma de facilitar a tão desejada articulação teoria e prática, visto que se caracteriza como uma das formas de apreensão da realidade epermite o diálogo entre o campo formal do conhecimento e o campo de trabalho, e com seus diferentes atores. É nesse aspecto que a Pedagogia da Alternância, como princípio da Residência Pedagógica,constitui-se uma proposta pedagógica e metodológica que inclui dialogicidade e problematização do conhecimento a partir da realidade, promovendo a construção de conhecimentos a respeito da realidade escolar e sua relação com o todo, com a totalidade do conhecimento, tendo como foco central o trabalho docente e sua realidade e assumindo uma formação que tem o trabalho como princípio educativo.

\section{Trabalho pedagógico}

Junto com o princípio da Alternância, apresentoo trabalho como princípio de formação. Aqui, trataremos do trabalho pedagógico com características ontológicas e históricas, estas porque são decorrentes de um processo dialético desenvolvido ao longo do tempo e da ação dos próprios homens e aquelas porque o 
resultado dessa interação é a constituição dos seres humanos como propriamente humanos. Saviani (2007, p. 154) explica o elo entre o trabalho e a sua dimensão educativa da seguinte forma:

Se a existência humana não é garantida pela natureza, não é uma dádiva natural, mas tem de ser produzida pelos próprios homens, sendo, pois, um produto do trabalho, isso significa que o homem não nasce homem. Ele forma-se homem. Ele não nasce sabendo produzir-se como homem. Ele necessita aprender a ser homem, precisa aprender a produzir sua própria existência. Portanto, a produção do homem é, ao mesmo tempo, a formação do homem, isto é, um processo educativo. A origem da educação coincide, então, com a origem do homem mesmo.

Sobre a característica de ser pedagógico, refere-se à relação ensino-aprendizagem que é carregado de intencionalidades, sendo portanto, político e orientado a um processo de produção de conhecimentos. É preciso observar que nem todo trabalho docente se materializa como pedagógico, pois pode se apresentar desconexo com a aprendizagem do sujeito. Ferreira $(2008$, p. 178) propõe a seguinte compreensão de pedagógico:

[...] é todo o pensar-agir da escola com o intuito de produzir conhecimento. Porém, não é pedagógico o pensar-agir, embora muito bem organizado, incoerente com a expectativa de produção do conhecimento dos sujeitos da aula. Percebe-se, então, não haver como dissociar uma concepção de pedagógico do espaço, do tempo e do trabalho realizado pela escola. Pedagógico é a articulação desses fatores, objetivando a produção do conhecimento. Afinal, se os sujeitos estudantes ingressam na escola é porque intencionam aprender. E aprender é um complexo movimento de linguagens em interlocução, subjetividades em interação e historicidades que se entrelaçam, no intuito de ampliar as compreensões de mundo, inserirem-se, cada vez mais, na cultura e "genteificar-se" ainda mais.

Outro cuidado que se deve ter ao tratar do trabalho pedagógico é a aproximação entre trabalho pedagógico e prática pedagógica, tratados como sinônimos e poucas vezes diferenciados. A opção por prática consome significativamente o aspecto ontológico contido na categoria trabalho e, nesse caso, se o trabalho pedagógico é empregado como sinônimo de prática pedagógica, os trabalhadores parecem ter possibilidades menores de se autoproduzirem no e a partir de seu trabalho. Desse modo, essa pouca ênfase e esclarecimento de sentidos sobre trabalho pedagógico, tratando-o não raramente como prática pedagógica sem esclarecer a diferenciação, impossibilita pensar para um estágio além, o de práxis pedagógica, o que implicaria a sua integralização como unidade da teoria e da prática.

O trabalho pedagógico, portanto, é mais amplo que a prática pedagógica, pois envolve todas as atividade do ser docente, especificamente a intencionalidade da formação expressa no planejamento;na participação ena elaboração e execução do projeto político;no envolvimento e trabalho com a comunidade;na escolha curricular de conteúdos, de atividades e da avaliação;no planejamento coletivo e individual;na articulação com os pares; e na intencionalidade para com a função da escola, da educação e do professor, entre outros.

Nesse sentido, esse princípio na Residência Pedagógica restaura a função do professor ao trazer para o centro da sua atividade o trabalho pedagógico; portanto, a tarefa dos residentes, preceptores e professores orientadores não pode ser restrita a pensar e investir apenas nos aspectos metodológicos das disciplinas específicas, ou mesmo ter apenas a sala de aula como referência, ou ainda ter foco em elaborar e realizar projetos educativos. Essas são atividades pertinentes desde que nasçam da compreensão e da vivência do trabalho pedagógico, cujaimersão na escola precisa se dar como participante de uma totalidade carregada de intencionalidades e contradições históricas e que se proponha a formar sujeitos para uma determinada visão de mundo e de sociedade;formação aqui assumida com um caráter emancipador. 


\section{Ensino- aprendizagem}

A questão do trabalho pedagógico nos remete à função do processo relacionada ao processo de ensinar. Roldão (2007, p.94) aborda que a função docente se caracteriza pela ação de ensinar, sendo que o conceito de ensinar não é definido de modo simples e fácil, pois há diferença entre "professar um saber" e fazer os outros aprenderem alguma coisa.Para a autora, ser professor é saber algo e saber ensinar esse algo a alguém. Diante disso, assumimos a intencionalidade do ensino como especificidade da docência e, para tanto, na formação inicial,o professor necessita se desenvolver como um intelectual crítico, cuja ação docente contemple o ato de educar em sua amplitude e complexidade, em que o profissional faça as escolhas subsidiado por um projeto educacional, pelo conhecimento científico e considerando a diversidade social, cultural, econômica e humana.

O fato é que, além de teorias, espaços e condições favoráveis ao trabalho pedagógico, para a especificidade do ato de ensinar existem, em cada momento histórico, os projetos de homem, de sociedade, de educação, dentre outros; projetos esses entendidos aqui como determinações pensadas e desenhadas pelos homens com a função de engendrar, na realidade social, as suas marcas e intenções políticas mais profundas. Nesse sentido, o ato de ensinar implica realizar escolhas a partir de um projeto de educação.

Uma questão necessária de se enfrentar é a compreensão da função do professor, entendida como mediação pedagógica. Assim, defendo o professor como aquele que ensina, embora tenha sido comum

[...] atribuir a Vigotski a idéia de que o professor tem um papel mediador; um elo entre o conhecimento e o aluno. Queremos trazer esse conceito para a discussão e contestar sua adequação ao pensar a atividade do professor na perspectiva histórico-cultural. Se, no processo do ensinar e do aprender, o aluno sempre se antecipa como oferta, na situação dialógica, interferindo efetivamente com restrições nas possibilidades de ação do professor, este não passa "em brancas nuvens" pela relação. Logo, não pode ser concebido como um mero elo intermediário, um negociador que, em princípio, permaneceria o mesmo pós-negociação. Nem o aluno, nem o professor são os mesmos depois do diálogo. O processo de ensinar e aprender, visto como unidade, parece, de fato, constituir um desafio à permanência da mesmice (TUNES; TACCA; BARTOLHO JUNIOR, 2005, p. 205).

Ao refletir sobre a realidade do ensino-aprendizagem, nesta relação entre professor e aluno, não estamos colocando-os em um nível de hierarquia, mas entendemos que há níveis diferentes de compreensão (conhecimento e experiência) da prática social.Entretanto, ambos, professor e aluno, participam do desejo da compreensão e reorganização da prática social enquanto ponto de chegada, transformando-se mutuamente e tornando possível transformar a realidade no processo. Assim, de forma sucessiva, outros desafios se constituirão em novos pontos de chegada; esse é o movimento dialético do ensinar-aprender.

No processo de ensino-aprendizagem existe um conteúdo histórico-cultural a ser socializado, uma experiência teórico-prática da docência a ser ensinada e apreendida (vivenciada). Nesse sentido, a Residência Pedagógica se torna um espaço de formação de professores com suportes e condições favoráveis para a aprendizagem da docência, especificamente no ato de ensinar e aprender. A alternância tempo universidade e tempo escola favorece a vivência com diferentes formas, metodologias e processos de ensinar, o que permite a problematização de tal prática e possíveis catarses que possibilitarão a práxis, pois, na sala de aula como um dos espaços do trabalho pedagógico, manifesta-se o ato de ensinar-aprenderna relação dinâmica entre os sujeitos. Issoindica possíveis mudanças qualitativas na visão de mundo e na ação do sujeito sobre o mundo, a partir 
das contradições presentes nesses espaços, gerando a transformação do professor, do conhecimento e do aluno, pois quem ensina, aprende e quem aprende, ensina, de forma que a teoria e aprática, em uma relação dialética, também concebem o ensino em uma estreita relação com a aprendizagem.

\section{Autonomia no trabalho docente}

O trabalho pedagógico que pressupõeo processo de ensinar-aprender envolve uma questão central: a autonomia;pela qual o professor se sente autor do processo e com condições para a realização dessa autoria. Nesse sentido, oriento-me pelo entendimento de que o trabalho docente não é mera execução, mas é, necessariamente, atividade criativa, embasada numa sólida formação que em síntese é a práxis.

A autonomia é compreendida como um processo de relação, no qual diferentes grupos que compõem uma sociedade negociam seus diversos interesses, tanto particulares quanto gerais. Nessa direção, Martins (2002) vê a autonomiacomo uma construção histórica influenciada por fatores culturais, econômicos e políticos que determinam a sociedade no decorrer de sua existência. O conceito de sujeito autônomo, portanto, envolve a ideia de responsabilidade social, pois requer compromisso daqueles que participam do processo decisório com questões que vão além de seus próprios interesses. Por isso, longe de ser um empreendimento individual, a atitude autônoma necessita estar vinculada a uma sensibilidade ética capaz de entender o outro e com disposição para a busca do consenso social.

Nesse sentido, quando falamos de autonomia docente, entendo como liberdade e poder do professor para organizar o trabalho pedagógico relacionado com as dimensões éticas da vivência de sua profissão, e, portanto, referenciada ao coletivo e à função social da escola e construída como decisão reflexiva e como construção contínua. Esta é uma visão de autonomia na qual se aposta na possibilidade de o professor exercer sua função profissional de forma absoluta (CONTRERAS, 2002).

Em algumas situações, a dinâmica de trabalho dos professores apresenta modelos automatizados, passados de geração a geração, e esperados por terem sido naturalizados. Essa perspectiva não permite o processo de autonomia, e nem o seu extremo que diz respeito às escolhas individuais, isoladas e circunscritas a uma concepção solipsistaque entende a autonomia como conjunto de ações que não dependem de outros fatores se não aqueles relativos ao conhecimento. Trabalhar na perspectiva da autonomia é enfrentar o senso comum e as visões reducionistas para a compreensão de uma autonomia referenciada no caráter processual, coletivo e enraizado numa função da escola como possibilidade de emancipação.

Sabemos que o trabalho docente estásubordinado à regulação pelo Estado que impõe limites à sua autonomia e, neste momento, é agravado decorrente das políticas para a formação inicial e continuada e pelos modelos de avaliação em larga escala que encerram o trabalho docente num pragmatismo-neotecnicista. Observa-se, assim, maior vigilância sobre o trabalho docente, visto que o Estado provoca uma separação maior entre os valores, projetos educacionais e perspectivas, colocando, de um lado, a administração - orçamento, recrutamento e gestão - e de outro, o professorado, com implicações sérias para o currículo, para as necessidades dos estudantes, o trabalho em classe e os registros escolares.

Ter o princípio da autonomia na Residência Pedagógica é construir uma formação em que o professor da educação básica, o preceptor, eo estudante da licenciatura, o residente, possam, no diálogo com a escola, comunidade e projeto político pedagógico, escolherem conteúdo e forma de ensinar, numa relação em que o ponto convergente é a aprendizagem do aluno.A autonomia, vista nesse contexto, refere-se às possibilidades 
de diferentes aprendizagens, por docentes e discentes, que serão constituídas no percurso do fazer pedagógico que busca associar uma concepção libertadora da prática de ensino com o processo que proporcione sua própria emancipação.

\section{Profissionalidade docente}

Tratamos neste estudo que a função do professor é ensinar. Em sua análise sobre a especificidade da docência, Roldão (2007) esclarece que, embora com variações conceituais e históricas, a natureza da função específica desse profissional tem se consolidado como a ação de ensinar. É preciso cuidar ao usar o conceito de ensinar, superando modelos transmissivos e redutores, para defini-lo em toda a sua complexidade, baseando-se não apenas em escolhas de práticas pedagógicas, posto que a profissionalidade é um

[...] conceito em construção que, inserido no âmbito maior da profissionalização, primeiramente caracteriza o processo inicial de socialização profissional, expressando as expectativas sociais externas através dos requerimentos para a formação e o exercício definidos pelo Estado. Esses requerimentos seriam definidos por uma profissionalidade científica ligada a uma noção de qualificação, pautada por exigências juridicamente reconhecidas através de títulos e cursos correspondentes. Expressam ainda as expectativas sociais internas do grupo de professores, que também se caracterizam por atitudes profissionais que este grupo social define para desenvolver suas atividades. Dessa forma, constitui-se num processo de melhoria de suas capacidades e seus conhecimentos, expressando saberes, comportamentos, destrezas e valores que constroem uma identidade e uma cultura próprias, definindo um profissional diferente de outro. (CRUZ, 2012, p. 80).

Dessa forma, compreendo o trabalho docente como princípio formativo para a docência.Entretanto, nas tensões e contradições presentes no quadro da reestruturação capitalista e no neoliberalismo, torna-se necessário discutir o conhecimento profissional não como um conjunto de competências e habilidades, mas que se traduz em um elemento distintivo do trabalho do professor. Não podemos conceituar o conhecimento profissional separado da natureza da função docente, e sim junto com os elementos históricos que marcam a atividade docente nas condições sociais, históricas e culturais.

Assim, avivência do trabalho (perejivanie2) que constitui a profissionalidade não é somente o espaço em que os conhecimentos são utilizados, ou as atividades práticas, ou ainda a perspectiva individual da identidade docente, e nem somente o "ser" do professor. Essa vivência é em si mesma um conhecimento do trabalho sobre os conhecimentos do fazer docente, a tomada de consciência para si, a apropriação e construçãodo ser professor,com vistas a produzir a prática coletiva do trabalho docente com especificidades singulares na relação com a universalidade, sendo que a profissionalidade marca o indivíduo singular a partir e com o universo da atividade docente.

Tomar o trabalho pedagógico como fonte de análise da profissionalidade no processo de formação inicial, refere-se àarticulação e compreensão a profissionalidade não restrita a elaborações individuais; por exemplo,de como o sujeito se identifica na profissão, mas é retomar a estrutura da profissão docente que implica em vários outros elementos: os subjetivos situados a partir da objetividade do trabalho (CRUZ, 2012). 
A questão da profissionalidade como princípio da Residência Pedagógica não se aproxima na perspectiva do engajamento profissional, tomando a subjetividade como elemento central, mas diz respeito "[..] à necessidade de o professor buscar a re-configuração dos modos de desenvolver suas ações e de se colocar na profissão em virtude das demandas específicas da sala de aula, da escola, de regulação e da sociedade de maneira geral." (CRUZ, 2012, p. 77). Ou seja, a profissionalidade se concebe na relação dialética objetiva e subjetiva que acontece no trabalho docente, cuja constituição tem elementos de ser e estar na profissão.

A intencionalidade da proposta de trazer a categoria profissionalidade é que a Residência Pedagógica construída na alternância pode colaborar para a compreensão de como as atividades docentes se realizam, integram e constituem o próprio ser docente,ou seja, permite a intenção e a ação de vivenciar como os professores produzem, incorporam, aplicam e transformam, no cotidiano, a si mesmos, seu coletivo e suas práticas. Essa profissionalidade, que é inaugurada na formação inicial produzidapela docência num sentido integral de trabalho pedagógico,constitui-se em uma ação intencionalizada, visando a articulação entre a epistemologia e a prática, e incorporando, portanto, elementos objetivos e subjetivos do trabalho docente, o que permite ao futuro professor se colocar de forma contextualizada dentro de uma dinâmica processual e numa perspectiva material e interdisciplinar o ser e estar numa profissão.

\section{Considerações finais}

Neste estudo, a discussão esteve voltada para o contexto formativo dos cursos de licenciatura, especificamente para o tema da Residência Pedagógica, buscando compreender como, a partir de uma perspectiva conceitual-metodológica, pode ser conduzida a formação dos futuros docentes, tendo como eixo uma formação de caráter emancipador.

Ao fazer uso do estudo bibliográfico sobre o tema, a intenção não foi levar a comunidade formadora, a universidade e a escola a se conformarem com o descoberto pronto, mas que por meio da discussão de princípios formativos, a construção de projetos de Residência Pedagógica na formação inicial sejam elaborados e executados com muita autonomia, construindo experiências diversas e de qualidade na formação. $\mathrm{Na}$ minha compreensão, o movimento de elaborar princípios formativos para a Residência Pedagógicaapresenta claramente o projeto de formação de professores, cuja intencionalidadedefendemos e, dialeticamente, possibilita a construção de um projeto prenhe de tais intencionalidades em ação - mostrando as razões para o que faz. Destaco ainda, que os aspectos aqui apresentados permitem indagações e principalmente discussões e argumentação em torno de novos princípios, pensando no que é genérico e específico à docência.

Enfim, entendo que não podemos manter a hegemonia consensual da regulação do Estado. É necessário, mesmo em programas governamentais, construir os processos de resistência e ocupação dos espaços. Que sejamos combatentes e que todos e todas possam ter uma formação na condição de dirigentes, mesmo que ainda não venham a ser; mas possa, assim, dirigir seus dirigidos (GRAMSCI, 2006).

\section{REFERÊNCIAS}

ARAÚJO, Polliana Rocha Dias. Residência Docente. 2016. Monografia (Trabalho de Conclusão de Curso). Universidade de Brasília, Brasília, 2016. Disponível em: Acesso em:

BRASIL. Coordenação de Aperfeiçoamento de Pessoal de Nível Superior.Portaria $n^{\circ} 38$, de 28 de fevereiro de 2018. Institui o Programa Residência Pedagógica. Brasília: CAPES,2018a. 
Edital Capes n 06/2018. Chamada Pública para apresentação de propostas no âmbito do Programa de Residência Pedagógica. Brasília: CAPES, 2018b.

Edital n 01/2020. Programa de Residência Pedagógica. Brasília: CAPES, 2020.

CANDAU, Vera .Maria .; LELIS, Isabel Alice. A Relação Teoria-Prática na Formação do educador. In: CANDAU, Vera Maria (Org.). Rumo a uma Nova Didática. 10. ed. Petrópolis: Vozes. 1999. p.56-72.

CONTRERAS, José. A autonomia de professores. Trad. Sandra Trabucco. 2. ed. São Paulo, SP: Editora Cortez, 2012.

COSTA, Elisangela André da Silva et al. (Orgs.) Programa Residência Pedagógica-UNILAB: os desafios de ensinar e aprender a profissão professor (a) à luz da diversidade [recurso eletrônico] Porto Alegre, RS: Editora $\mathrm{Fi}, 2020$.

COUTINHO, Carlos Nelson. Gramsci: um estudo sobre seu pensamento político. Rio de Janeiro, 1989.

CRUZ, Shirleide Pereira da Silva. A construção da profissionalidade polivalente na docência nos anos iniciais do ensino fundamental: sentidos atribuídos às práticas por professoras da rede municipal de ensino do Recife. Recife, 2012. 278f. Tese (doutorado) - UFPE, Centro de Educação, Programa de Pós-graduação em Educação. Recife, 2012.

CURADO SILVA, Kátia Augusta Curado Pinheiro Cordeiro da.Professores com formação Stricto sensu e o desenvolvimento da pesquisa na educação básica da rede pública de Goiânia 2008. 292 f. Tese (Doutorado em Ciências Humanas) - Universidade Federal de Goiás, Goiânia, 2008.

Políticas de formação de professores: construindo resistências. Revista Retratos da Escola, Brasília, v. 12, n. 23, p. 307-320, jul./out. 2018.

Epistemologia da práxis na formação de professores: perspectiva crítico-emancipadora. São Paulo: Mercado de Letras, 2019.

CURADO SILVA, Katia Augusta Curado Pinheiro da; CRUZ, Shirleide Pereira. A residência pedagógica na formação de professores: história, hegemonia e resistências. Momento - Diálogos em Educação, ABNT, v. 27, n. 2, p. 227-247, ago. 2018. ISSN 2316-3100. Disponível em: <https://periodicos.furg.br/momento/article/ view/8062>. Acesso em: 03 out. 2020.

DUARTE, Stephanie Marina Cardoso Araújo. Tornar-se docente: o início da carreira e o processo de constituição da especificidade da ação docente. 2014. 151 f., il. Dissertação (Mestrado em Educação) - Universidade de Brasília, Brasília, 2014.

ESTEVAM, Dimas de Oliveira. Casa Familiar Rural: a formação com base na Pedagogia da Alternância. Florianópolis, SC: Insular, 2003.

FARIA, Juliana Batista.; DINIZ-PEREIRA, Júlio Emilio. Residência pedagógica: afinal, o que é isso? Revista Educação Pública. Cuiabá, v. 28, n. 68, p. 333-356. 2019. 
FERREIRA, Liliana Soares. Trabalho pedagógico. In: OLIVEIRA, Dalila Andrade. et al.Dicionário trabalho, profissão e condição docente. Belo Horizonte: Faculdade de Educação UFMG, 2010.

FREIRE, Paulo. Educação como Prática da Liberdade. 9. ed. Rio de Janeiro: Paz e Terra, 1979.

GRAMSCl, Antonio. Cadernos do Cárcere, Volume 2: Os Intelectuais. O Princípio Educativo. Jornalismo. 4. ed. Tradução de Carlos Nelson Coutinho. Co-edição de Luiz Sérgio Henriques e Marco Aurélio Nogueira. Rio de Janeiro: Civilização Brasileira, 2006.

MARTINS, Ângela Maria. Autonomia e educação: a trajetória de um conceito. In:Cadernos de Pesquisa, São Paulo, n. 115, 2002, p. 207-232.

QUEIROZ, João Batista de. Construção das Escolas Famílias Agrícolas no Brasil: ensino médio e educação profissional. 2004. Tese (Doutorado em Educação) - Universidade de Brasília (UnB), Brasília, DF, 2004.

ROLDÃO, Maria do Céu Roldão. Função docente: natureza e construção do conhecimento profissional. Revista Brasileira de Educação v. 12, n. 34 jan./abr. 2007

SAVIANI, Dermeval. História das ideias pedagógicas no Brasil. 3. ed. rev. Campinas, SP: Autores Associados, 2007.

TUNES, Elizabeth; TACCA, Maria Carmen VR e BARTHOLO JUNIOR, Roberto dos Santos. O professor e o ato de usar. Cafajeste. Pesqui. [conectados]. 2005, vol.35, n.126 [cited 2020-10-13], pp.689-698.

VASQUEZ, Antonio Sanchez. Filosofia da práxis. Rio de Janeiro: Paz e Terra, 1977

ZEICHNER, Ken. Repensando as conexões entre a formação na universidade e as experiências de campo na formação de professores em faculdades e universidade. Revista Educação, Santa Maria, v. 35, n. 3, p. 479-504, set./dez. 2010 